\title{
Dinâmica das áreas verdes do perímetro urbano de Muqui/ES, Brasil
}

\begin{abstract}
Diante do crescimento desordenado de várias cidades, o objetivo deste trabalho foi estimar e mapear as áreas verdes urbanas do município de Muqui (ES), com vistas a subsidiar melhorias na qualidade de vida e ambiental. Os procedimentos foram executados no programa computacional ArcGIS ${ }^{\oplus}$. No GEOBASES/ES e IJSN foram adquiridas: imagem aérea do local acerca do mapeamento realizado nos anos de 2012-2015 e uma feição de área urbana do município. As áreas verdes foram classificadas em: arborização, faixa verde (gramíneas), praças/parques urbanos e canteiros centrais/rotatórias. A identificação das classes ocorreu através da fotointerpretação na escala 1:1000. Foram estimados: Índice de Áreas Verdes Totais (IAVT) e Índice de Áreas Verdes Recreativas (IAVR). As áreas verdes foram mapeadas e quantificadas. Há maior predominância da arborização (62,17\% do total de áreas verdes), seguido da faixa verde (37,09\%). Os valores do IAVT e IAVR foram iguais a $77,14 \mathrm{~m}^{2} /$ habitante e $0,56 \mathrm{~m}^{2} /$ habitante, respectivamente. O IAVT esteve muito acima do mínimo estabelecido pela Organização Mundial da Saúde e Sociedade Brasileira de Arborização Urbana. Todavia, o IAVR encontrado foi muito baixo, devido à existência de apenas duas praças na cidade, sendo necessária a criação de novas praças e parques urbanos e educação ambiental voltada à importância das áreas verdes, como forma de melhorar a qualidade de vida atrelada à função ambiental das áreas verdes.
\end{abstract}

Palavras-chave: Arborização; Espaço Urbano; Meio Ambiente; Qualidade Ambiental.

\section{Dynamics of green areas of the urban perimeter of Muqui/ES, Brazil}

Given the disordered growth of several cities, the objective of this work was to estimate and map the urban green areas of the municipality of Muqui (ES), with a view to subsidizing improvements in quality of life and the environment. The procedures were performed in the computer program ArcGIS ${ }^{\oplus}$. In GEOBASES/ ES and IJSN, were acquired: aerial image of the site about the mapping carried out in the years 2012-2015 and a feature of urban area of the municipality. The green areas were classified as: afforestation, green belt (grasses), squares/urban parks and central/roundabouts. Class identification occurred through photointerpretation on the 1:1000 scale. Total Green Area Index (TGAI) and Recreational Green Area Index (RGAI) were estimated. The green areas were mapped and quantified. There is a greater predominance of afforestation $(62,17 \%$ of the total green areas), followed by the green belt (37,09\%). The TGAI and RGAI values were equal to 77,14 $\mathrm{m}^{2} /$ inhabitant and $0,56 \mathrm{~m}^{2} /$ inhabitant, respectively. The TGAI was well above the minimum established by the World Health Organization and the Brazilian Society of Urban Forestation. However, the RGAl found was very low, due to the existence of only two squares in the city, requiring the creation of new squares and urban parks and environmental education focused on the importance of green areas, as a way to improve the quality of life linked to the function green areas.

Keywords: Afforestation; Urban Space; Environment; Environmental Quality.

Topic: Desenvolvimento, Sustentabilidade e Meio Ambiente

Reviewed anonymously in the process of blind peer.

Caio Henrique Ungarato Fiorese (D)

Centro Universitário São Camilo, Brasil

http://lattes.cnpq.br/0545804621047516

http://orcid.org/0000-0001-6866-0361

caiofiorese@hotmail.com
Received: 10/05/2020

Approved: 06/06/2020
Referencing this:

FIORESE, C. H. U.. Dinâmica das áreas verdes do perímetro urbano de Muqui/ES, Brasil. Revista Ibero-Americana de Ciências Ambientais, v.11, n.4, p.416-423, 2020. DOI: http://doi.org/10.6008/CBPC2179$\underline{6858.2020 .004 .0034}$ 


\section{INTRODUÇÃO}

Desde a década de 1970, as cidades brasileiras têm sofrido transformações intensas. A busca pela compreensão da diversidade dos aspectos do espaço urbano, relacionados às suas dimensões socioambientais, tornou-se uma preocupação cada vez mais presente no planejamento e na gestão urbana. Os temas relacionados à qualidade ambiental das áreas urbanas vêm sendo debatidos por diversos pesquisadores nos níveis técnicos e científicos. Dentre os temas de relevância, a vegetação intraurbana ganhou destaque nos últimos anos em virtude das funções que esta pode exercer na melhoria das condições do ambiente urbano (BARGOS et al., 2011).

A qualidade de vida urbana está diretamente atrelada a vários fatores que estão reunidos na infraestrutura, no desenvolvimento econômico-social e àqueles ligados à questão ambiental. No caso do ambiente, as áreas verdes são elementos fundamentais para o bem-estar da população, pois influencia diretamente a saúde física e mental da população (LOBODA et al., 2005).

A presença de árvores nas cidades é essencial na estrutura e dinâmica da paisagem urbana que, por seus atributos, colaboram para melhoria da qualidade de vida humana e ambiental nas cidades. Além do mais, certifica a melhoria da qualidade de vida da população e qualidade ambiental nas cidades, seja no âmbito social, ecológico e paisagístico. Exerce benefícios importantes ao meio urbano, ao melhorar as condições atmosféricas e o balanço hídrico e desempenhar o equilíbrio edáfico e microclimático. Serve também como atrativo para avifauna e bem-estar psicológico da população (LIMA NETO, 2011).

As áreas verdes urbanas assumiram um papel de destaque para a manutenção e melhoria da qualidade ambiental urbana. Elas interferem diretamente na qualidade de vida dos seres humanos contribuindo para a amenização dos problemas de um processo de urbanização acelerado e que se deu, na maioria das vezes, sem um planejamento adequado que levou a um aumento da poluição atmosférica e das águas, das alterações no microclima, das inundações, da falta de espaços livres públicos e de vegetação, dentre uma gama de danos que possuem escalas que vão do local ao regional (BARGOS et al., 2011).

O maior problema da vegetação é quando ela está inserida em áreas urbanas. A degradação antrópica que recebe é praticamente inevitável, pois, mesmo que protejam a área com vigilantes e cercas para evitar a invasão de populares quando se fala em áreas protegidas, a área estará sempre sujeita a modificações adversas provenientes de ações antrópicas, justamente por estar inserida em locais com forte adensamento populacional. Além destas áreas, a vegetação contida em áreas de preservação permanente e em praças e calçadas também está sujeita a essas modificações (RUBIRA, 2016).

Como forma de verificar as condições ambientais de uma cidade, o estudo do verde urbano pode ser utilizado como parâmetro em análises quali-quantitativas. $O$ uso da vegetação como referência de análise permite mensurar a qualidade ambiental urbana, já que promove uma série de benefícios ao ser humano, extrapolando questões estéticas ou sentimentais (PANCHER et al., 2012). Assim, o estudo da percepção dos problemas ambientais nas áreas verdes urbanas é fundamental para compreender melhor as inter-relações entre o homem e o ambiente e aferir até que ponto os alunos que atingem esse nível de ensino tem a noção 
da importância das áreas verdes urbanas numa cidade (MUACUVEIA, 2017).

A mensuração de variáveis através de fotografias aéreas ainda é uma atividade não muito explorada na arborização viária e tem-se mostrado de grande potencialidade em outras medições realizadas no ambiente urbano. A utilização conjunta de dados mensurados nos inventários tradicionais com as informações provenientes do processamento digital das imagens em ambiente SIG, quando aplicados, diminui os custos obtidos nos inventários convencionais, pois a aferição através de imagens pode ser de maneira rápida (LIMA NETO, 2011). Considerando a relevância da temática e, com auxílio de geotecnologias, o objetivo deste trabalho foi mapear e estimar as áreas verdes urbanas do município de Muqui, estado do Espírito Santo, como forma de subsidiar melhorias quanto à qualidade de vida local.

\section{MATERIAIS E MÉTODOS}

O local de estudo compreendeu a área urbana do município de Muqui, que está localizado na mesorregião Sul do Estado do Espírito Santo. Localiza-se a uma latitude sul de 20 ,56' e 54" e a uma longitude oeste de Greenwich de $41^{\circ}$, 20' e 38". Com uma população de 13670 habitantes, segundo o Instituto Brasileiro de Geografia e Estatística (IBGE, 2010), possui clima quente, com temperatura média anual de $23^{\circ} \mathrm{C}$. A cafeicultura e a pecuária leiteira são as principais atividades econômicas, predominando a agricultura familiar (INCAPER, 2010). A Figura 1 apresenta a localização de Muqui e de sua área urbana.

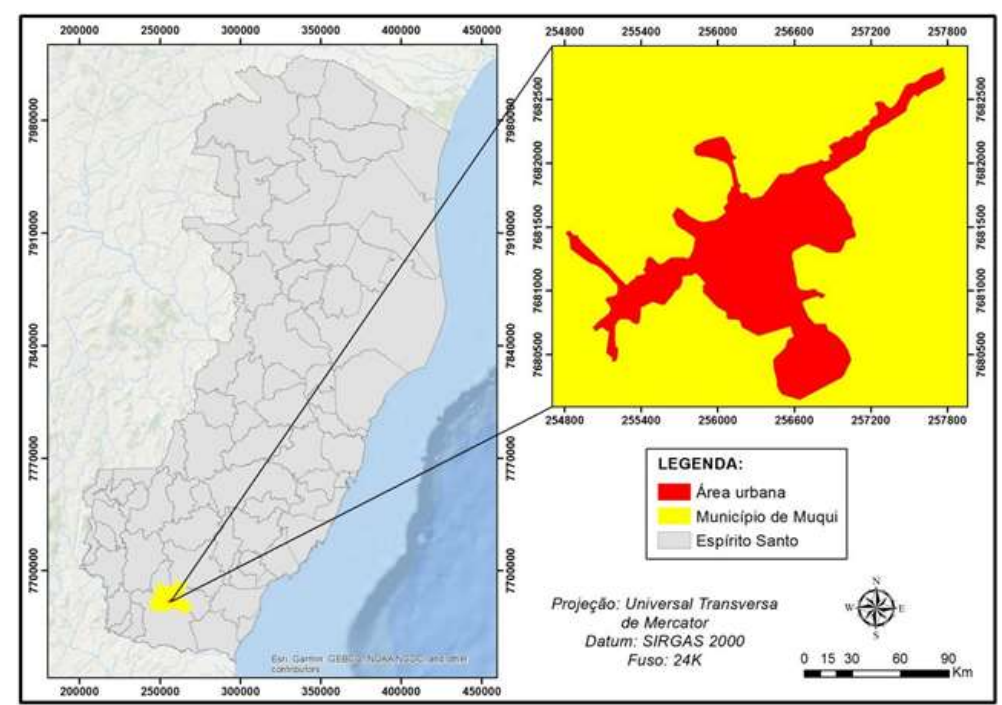

Figura 1: Localização do município de Muqui e de sua zona urbana.

Os procedimentos ocorreram no programa computacional $\operatorname{ArcGIS}^{\circledast}$. A base de dados digitais foi adquirida junto ao Sistema Integrado de Bases Geoespaciais do Estado do Espírito Santo (GEOBASES) e ao Instituto Jones dos Santos Neves (IJSN). No GEOBASES, foram adquiridas feições acerca dos municípios do Estado do Espírito Santo e imagens aéreas referentes à zona urbana de Muqui (ES), acerca do mapeamento dos anos 2012-2015, com resolução espacial de 1 m e 0,25 m, respectivamente. No sítio eletrônico do IJSN, foram adquiridos os dados referentes à área urbana do município, que auxiliou nos procedimentos posteriores.

De posse do banco de dados, foi possível descrever e caracterizar as classes de áreas verdes para o 
município de Muqui, conforme a literatura pesquisada. A Tabela 1 apresenta a descrição e as classes.

Tabela 1: Descrição das classes de áreas verdes urbanas.

\begin{tabular}{|l|l|}
\hline Classe & Descrição \\
\hline Área arborizada & $\begin{array}{l}\text { Espaços públicos e particulares que contenham vegetação nativa ou exótica, excetuando-se a arborização } \\
\text { de praças e parques urbanos }\end{array}$ \\
\hline Faixa de verde & $\begin{array}{l}\text { Constituída por gramados e forrações (campos de futebol e de golfe, por exemplo), com ausência de } \\
\text { arbustos e árvores }\end{array}$ \\
\hline Praças & Apresentam função recreacional, podendo abrigar equipamentos como bancos, mesas, academias, etc. \\
\hline $\begin{array}{l}\text { Canteiros centrais e } \\
\text { rotatórias }\end{array}$ & $\begin{array}{l}\text { Áreas que não possuem caráter conservacionista nem recreacionista, cumprindo, portanto, função } \\
\text { ornamental }\end{array}$ \\
\hline
\end{tabular}

Fonte: Adaptado de Loboda et al. (2005).

As classes de áreas verdes foram identificadas através da fotointerpretação das feições na escala 1:1000. Para auxiliar na interpretação dos resultados, as classes foram mapeadas e quantificadas, em porcentagem (\%) e metros quadrados $\left(\mathrm{m}^{2}\right)$. Em seguida, foram estimados o Índice de Áreas Verdes Totais (IAVT) e o Índice de Áreas Verdes Recreativas (IAVR), com base na metodologia empregada por vários autores, como Harder et al. (2006) e Pirovani et al. (2012), a partir das equações (1) e (2).

$$
\begin{aligned}
& I A V T=\sum \frac{A V}{N} \\
& I A V R=\sum \frac{A R}{N}
\end{aligned}
$$

Em que: $A V=$ total de áreas verdes urbanas $\left(e m m^{2}\right) ; A R=$ áreas verdes recreativas $\left(e \mathrm{~m} \mathrm{~m}^{2}\right) ; \mathrm{N}=$ número de habitantes da cidade de Muqui. O número de habitantes foi consultado no sítio eletrônico do Instituto Brasileiro de Geografia e Estatística (IBGE, 2010), referente ao censo demográfico do ano de 2010. Os resultados obtidos para o IAVT e IAVR foram avaliados com base nos números mínimos de áreas verdes por habitante recomendados pela Organização Mundial da Saúde (OMS) e Sociedade Brasileira de Arborização Urbana (SBAU), além de comparação com trabalhos similares encontrados na literatura.

\section{RESULTADOS E DISCUSSÃO}

As áreas verdes da zona urbana do município de Muqui constituem um total de $718.069,49 \mathrm{~m}^{2}$, abrangendo $41,79 \%$ do espaço urbano local. Há maior predominância de arborização, com $62,17 \%$, ao passo que a faixa de verde ocupa 37,09\%. De grande relevância, as praças e parques urbanos ocupam apenas 0,73\% do total de áreas verdes. A Tabela 2 mostra os dados de área para cada classe de áreas verdes.

Tabela 2: Área, em metros quadrados e porcentagem, para cada classe de áreas verdes.

\begin{tabular}{|l|l|l|}
\hline Classes & Área $\left(\mathbf{m}^{\mathbf{2}}\right)$ & Área $(\%)$ \\
\hline Área arborizada & $446.430,66$ & 62,17 \\
\hline Faixa de verde & $266.302,00$ & 37,09 \\
\hline Praças & 5241,83 & 0,73 \\
\hline Canteiros centrais e rotatórias & 95,00 & 0,01 \\
\hline Total & $718.069,49$ & 100 \\
\hline
\end{tabular}

Esses resultados foram semelhantes aos obtidos por Fiorese et al. (2018). Em estudos acerca da arborização urbana do município de Mimoso do Sul (ES), os mesmos autores estimaram percentuais de arborização e faixa de verde iguais a 36,79\% e 63,21\%, respectivamente, considerando apenas as duas classes de áreas verdes. Dessa forma, a arborização contida em calçadas, áreas de preservação permanente e 
quintais residenciais assume um papel fundamental na composição das áreas verdes da cidade de Muqui.

Quanto à faixa de verde, seu papel ambiental é relevante. Segundo a Sociedade Internacional de Arboricultura (SIA, 2013), as gramíneas e os gramados exercem vários benefícios, tais como: retirada de dióxido de carbono da atmosfera, produção de oxigênio, resfriar o ar transformando água em vapor d'água, filtragem de partículas de poeira e material particulado, retenção de gases poluentes e redução da erosão do solo. Portanto, sua predominância na cidade de Muqui é importante para a melhoria da qualidade ambiental, além de minimizar problemas resultantes da ação antrópica como, por exemplo, a impermeabilização do solo a partir das construções civis.

Os canteiros centrais e as rotatórias, apesar de melhorarem a qualidade do ar, assumem função paisagística (SANTOS et al., 2018). O percentual dessa classe foi muito baixo, observado em apenas uma rotatória da cidade, sendo que, entre as classes de áreas verdes, a classe "canteiros centrais e rotatórias" é a que menos interfere para alavancar o Índice de Áreas Verdes e a qualidade ambiental de Muqui. De acordo com os dados do Instituto Brasileiro de Geografia e Estatística (IBGE, 2010), a zona urbana do município de Muqui possui uma população de 9.309 habitantes. A Tabela 3 apresenta os valores estimados para o Índice de Áreas Verdes Totais (IAVT) e o Índice de Áreas Verdes Recreativas (IAVR).

Tabela 3: Valores do IAVT e IAVR para cada mapeamento.

\begin{tabular}{|l|l|}
\hline Índices & Valor \\
\hline Índice de Áreas Verdes Totais (IAVT) & $77,14 \mathrm{~m}^{2} / \mathrm{hab}$ \\
\hline Índice de Áreas Verdes Recreativas (IAVR) & $0,56 \mathrm{~m}^{2} / \mathrm{hab}$ \\
\hline
\end{tabular}

O valor obtido é superior ao estimado em outras cidades, como Mimoso do Sul (16,69 $\mathrm{m}^{2} / \mathrm{habitante}$, segundo Fiorese et al. (2018)) e Itaú de Minas (68,057 m²/hab, segundo Santos et al. (2018)), significando um fator positivo para a qualidade de vida e ambiental desta cidade, comparando com outras. No entanto, salienta-se que a grande diferença entre os valores de IAV para as diferentes cidades decorre principalmente dos critérios para categorização das chamadas áreas verdes urbanas e das metodologias utilizadas para o seu cálculo (LUCON et al., 2013). A quantificação das áreas verdes depende das classes a serem consideradas durante o estudo, porém, este índice, no intuito comparativo, é relevante para avaliar questões como qualidade ambiental e planejamento urbano entre cidades.

Conforme Lucon et al. (2013) e a Sociedade Brasileira de Arborização Urbana (SBAU, 1996), a Organização Mundial da Saúde (OMS) e a Sociedade Brasileira de Arborização Urbana (SBAU) consideram adequados os valores iguais ou acima de $12 \mathrm{~m}^{2} / \mathrm{hab}$ e $15 \mathrm{~m}^{2} / \mathrm{hab}$, respectivamente. Portanto, a cidade de Muqui apresenta valor de IAVT muito superior ao mínimo recomendado, indicando ótima quantidade de espaços verdes locais, independentemente de sua função (recreação e ornamentação, por exemplo). Portanto, as áreas verdes locais, segundo Lucon et al. (2013), cumprem adequadamente as funções social e ambiental, fornecendo bem-estar, isolamento acústico e microclima como alguns dos benefícios.

Todavia, o valor estimado para o IAVR foi inferior a $1 \mathrm{~m}^{2} /$ habitante e muito aquém dos valores mínimos estabelecido pela OMS e SBAU. Dessa forma, é importante ressaltar que, sendo a maior composição por arborização urbana e a baixa abrangência de praças e parques, as áreas verdes locais não assumem um 
grande papel de recreação, o que contribuiria mais para melhorar a qualidade de vida da população de Muqui. Os parques urbanos são áreas verdes que podem trazer qualidade de vida para a população, pois proporcionam contato com a natureza e suas estruturas e qualidade ambiental, quando adequadas e atrativas, são determinantes para a realização de atividade física e o lazer (SZEREMETA et al., 2013). A ampliação ou delimitação de parques urbanos seria uma ótima sugestão diante do baixo IAVR estimado, diante da relevância das praças e parques para uma cidade, independentemente de seu tamanho ou das perspectivas de desenvolvimento para os próximos anos.

A responsabilidade de planejar, criar e gerir esses espaços de singular importância para o bem-estar social é do poder municipal, sendo que a gestão e o planejamento das áreas verdes urbanas devem estar previstas no Plano Diretor (SILVA et al., 2016). Em toda e qualquer cidade, o planejamento e a gestão ambiental das áreas verdes devem considerar, cada vez mais, a necessidade de incluir a visitação pública como um elemento fundamental para a difusão de uma sensibilidade ambiental, passando a investir na infraestrutura local necessária (PINA, 2011).

A área urbana de Muqui é constituída por apenas duas praças, denominadas Praça do Centro e Praça da Boa Esperança. Embora seja uma cidade de considerado baixo número de habitantes, a delimitação e criação de novas praças e parques urbanos seriam de grande relevância, servindo de forma mais adequada a população local com novas áreas de recreação. No entanto, a criação dessas praças poderia priorizar as áreas em desenvolvimento e loteamento na cidade e, apesar dos investimentos poderem ser elevados, a função desses espaços seria crucial para melhorar a qualidade de vida e ambiental da cidade. As Figuras 2 e 3 apresentam as imagens da Praça do Centro e da Praça da Boa Esperança, respectivamente.

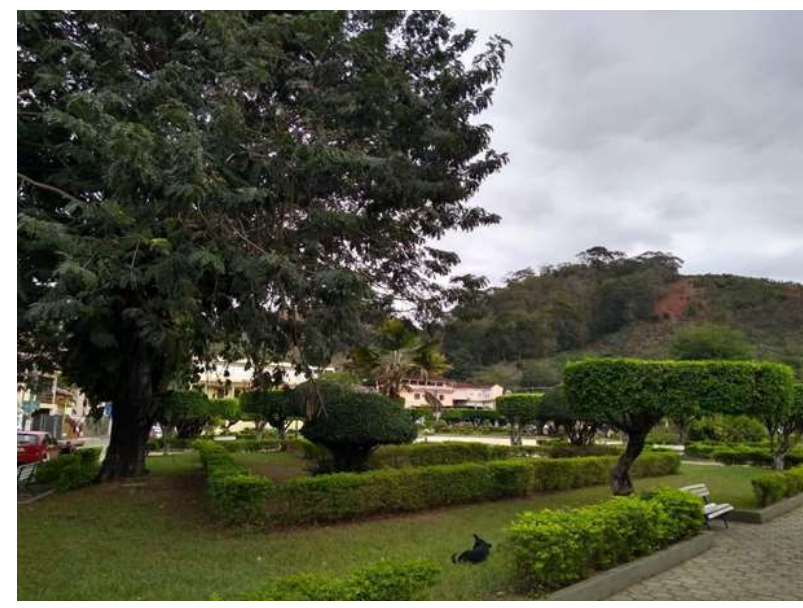

Figura 2: Praça do Centro.

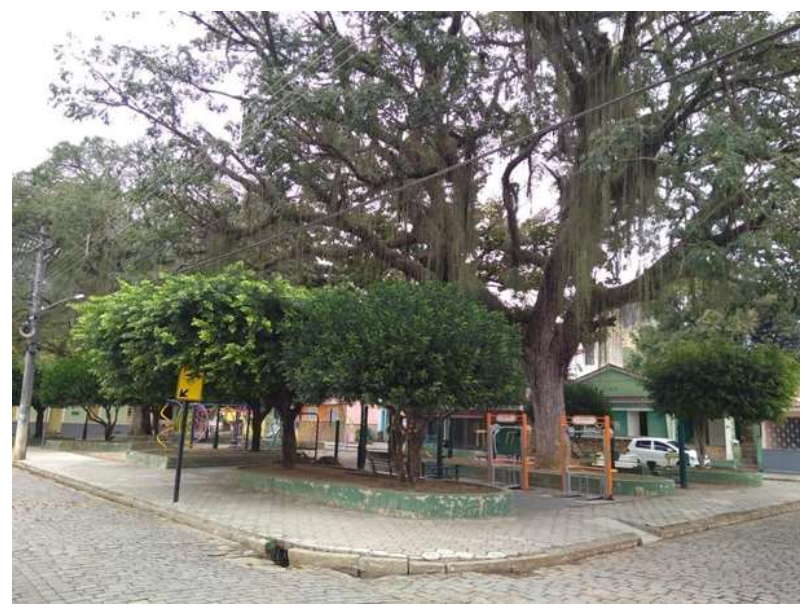

Figura 3: Praça da Boa Esperança.

Quanto à distribuição das áreas verdes, notou-se que, como há grande predominância de arborização de calçadas, quintais residenciais e vegetação contida em áreas de preservação permanente dos cursos hídricos locais, a arborização esteve disposta mais pontualmente na maior parte da cidade, estando mais aglomerada apenas próximo aos cursos hídricos locais e na parte central da zona urbana. A faixa verde está disposta predominantemente em campos de futebol, quintais residenciais, loteamentos não ocupados por edificações e, principalmente, na porção central da cidade. Além do mais, o baixo IAVR evidenciou, no mapeamento, a carência de praças e parques urbanos locais, embora seja uma cidade com baixo número de 
habitantes. A Figura 4 apresenta o mapeamento das áreas verdes da zona urbana de Muqui.

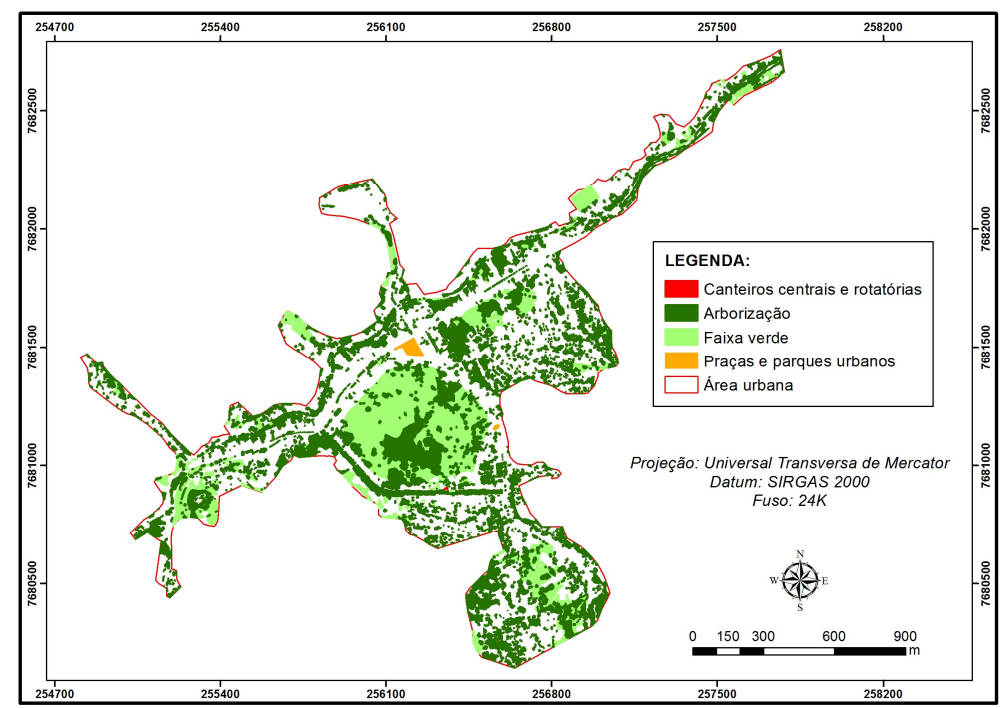

Figura 4: Distribuição espacial das classes de áreas verdes da cidade de Muqui (ES).

A fragmentação dos locais arborizados, como na área estudada, indica que a arborização urbana do município poderia ser melhorada por meio da criação de parques ecológicos na zona urbana e outras áreas de lazer que contemplem vegetação arbórea, trazendo, assim, vários benefícios quanto à qualidade de vida e ambiental do referido município (FIORESE et al., 2018). O que, para a cidade de Muqui, seria fundamental principalmente nos espaços que atualmente não dispõem dessas áreas, como nas porções sul, leste e oeste da cidade, como forma de fornecer aos moradores locais melhores condições para atividades recreativas e de lazer atreladas à função ambiental das praças e parques ecológicos.

Outro fator relevante é a ampliação da cobertura vegetal (FIORESE et al., 2018) em locais próximos aos cursos hídricos locais. Mesmo não possuindo função recreativa, de acordo com Costa et al. (1996), a cobertura vegetal nesses espaços atenua os processos erosivos e melhora a qualidade dos recursos hídricos e do ar. Para a cidade de Muqui, proteger e ampliar a vegetação nesses espaços significa melhorar a qualidade ambiental e de vida, além de melhorar o IAVT local.

Dada a preocupação em manter as áreas verdes urbanas, salienta-se também a aplicabilidade da educação ambiental com os moradores locais, voltada à importância das áreas verdes para determinada cidade (FIORESE et al., 2018). A importância da educação ambiental para a área urbana de Muqui está voltada, principalmente, a manter a arborização de calçadas, áreas de preservação permanente e quintais residenciais e, consequentemente, o elevado IAVT, dada a baixa disposição de praças e parques urbanos.

\section{CONCLUSÕES}

O Índice de Áreas Verdes Totais para a zona urbana de Muqui é muito satisfatório, estando acima dos valores mínimos estabelecidos pela Organização Mundial da Saúde e Sociedade Brasileira de Arborização Urbana. Portanto, esse quesito indica ótima predominância das áreas verdes, constituída, basicamente, por arborização (em calçadas, áreas de preservação permanente e quintais de residências) e faixa verde (gramíneas). Com isso, a distribuição da arborização esteve de forma mais pontual na maior parte da cidade, 
e concentrada para a faixa verde.

Todavia, o baixo Índice de Áreas Verdes Recreativas, composta por apenas duas praças, indica a necessidade de políticas públicas voltadas à ampliação e delimitação de novas áreas de praças e parques em locais que não se dispõem das mesmas, além da ampliação da cobertura vegetal próximo aos cursos hídricos locais e a prática de atividades voltadas à educação ambiental. Essas propostas contribuiriam para melhorar a qualidade ambiental e de vida da cidade, atrelando da forma mais correta possível a ação antrópica com a função ambiental exercida pelas áreas verdes.

\section{REFERÊNCIAS}

BARGOS, D. C.; MATIAS, L. F.. Áreas verdes urbanas: um estudo de revisão e proposta conceitual. Revista da Sociedade Brasileira de Arborização Urbana, Piracicaba, v.6, n.3, p.172-188, 2011.

COSTA, T. C. C..; SOUZA, M. G.; BRITES, R. S.. Delimitação e caracterização de áreas de preservação permanente, por meio de um Sistema de Informações Geográficas (SIG). In: SIMPÓSIO BRASILEIRO DE SENSORIAMENTO REMOTO, 8. Anais. Salvador: Instituto Nacional de Pesquisas Espaciais, 1996. p.121-127.

FIORESE, C. H. U.; MADEIRA, L.; SILVA-FILHO, G.; BINOTI, D. H. B.; MARTINS, L. D.. Áreas verdes urbanas e periurbanas do município de Mimoso do Sul/ES, Brasil. Enciclopédia Biosfera, Goiânia, v.15, n.28, p.97-110, 2018. DOI: http://doi.org/10.18677/EnciBio 2018B9

HARDER, I. C. F.; RIBEIRO, R. C. S.; TAVARES, A. R.. Índices de área verde e cobertura vegetal para as praças do município de Vinhedo, SP. Revista Árvore, Viçosa, v.30, n.2, p.277-282, 2006. DOI: http://doi.org/10.1590/S0100$\underline{67622006000200015}$

IBGE. Instituto Brasileiro de Geografia e Estatística. Sinopse do censo demográfico 2010: Espírito Santo. Vitória: IBGE, 2010.

INCAPER. Programa de assistência técnica e extensão rural PROATER 2011-2013: Muqui. Vitória: INCAPER, 2020.

LIMA NETO, E. M.. Aplicação do sistema de informações geográficas para o inventário da arborização de ruas de Curitiba, PR. Dissertação (Mestrado em Engenharia Florestal) - Universidade Federal do Paraná, Curitiba, 2011.

LOBODA, C. R.; ANGELIS, B. L. D.. Áreas verdes públicas: conceitos, usos e funções. Ambiência, Guarapuava, v.1, n.1, p.125-139, 2005.

LUCON, T. N.; PRADO FILHO, J. F.; SOBREIRA, F. G.. Índice e percentual de áreas verdes para o perímetro urbano de Ouro Preto/MG. Revista SBAU, Piracicaba, v.8, n.3, p.63-78, 2013. DOI: http://dx.doi.org/10.5380/revsbau.v8i3.66430
MUACUVEIA, R. R. M.. A inclusão do tema 'áreas verdes urbanas' no programa de ensino de geografia da $12^{a}$ classe em Moçambique. Revista Brasileira de Educação em Geografia, Campinas, v.7, n.14, p.161-184, 2017.

PANCHER, A. M.; ÁVILA, M. R.. O uso de geotecnologias na determinação do percentual de áreas verdes urbanas no município de Americana/SP. Geonorte, v.2, n.4, p.16621673, 2012.

PINA, J. H. A.. A influência das áreas verdes urbanas na qualidade de vida: o caso dos Parques do Sabiá e Victório Siquierolli em Uberlândia/MG. Dissertação (Mestrado em Geografia) - Universidade Federal de Uberlândia, Uberlândia, 2011.

PIROVANI, D. B.; SILVA, A. G.; OLIVEIRA, O. M.; CALIMAN, J. P.. Áreas verdes urbanas de Cachoeiro de Itapemirim, ES. Enciclopédia Biosfera, Goiânia, v.8, n.15, p.171-179, 2012.

RUBIRA, F. G.. Definição e diferenciação dos conceitos de áreas verdes/espaços livres e degradação ambiental/impacto ambiental. Caderno de Geografia, v.26, n.45, p.134-150, 2016. DOI: http://doi.org/10.5752/P.23182962.2016v26n45p134

SANTOS, C. D. M.; MAGRI, R. A. F.. Áreas verdes urbanas do município de Itaú de Minas/MG, Brasil. Enciclopédia Biosfera, Goiânia, v.15, n.27, p.42-53, 2018. DOI: http://doi.org/10.18677/EnciBio 2018A5

SILVA, A. D. P.; SANTOS, A. F.; OLIVEIRA, L. M.. Índices de área verde e cobertura vegetal das praças públicas da cidade de Gurupi, TO. Floresta, Curitiba, v.46, n.3, p.353-361, 2016. DOI: http://dx.doi.org/10.5380/rf.v46i3.40052

SBAU. Sociedade Brasileira de Arborização Urbana. Carta a Londrina e Ibiporã. Boletim Informativo, v.3, n.5, p.3, 1996.

SIA. Sociedade Internacional de Arboricultura. Árvores e gramados. SIA, 2013.

SZEREMETA, B.; ZANNIN, P. H. T.. A importância dos parques ecológicos e áreas verdes na promoção da qualidade de vida em cidades. Revista Ra' e Ga, Curitiba, v.29, p.177-193, 2013. DOI: http://dx.doi.org/10.5380/raega.v29i0.30747

A CBPC - Companhia Brasileira de Produção Científica (CNPJ: 11.221.422/0001-03) detém os direitos materiais desta publicação. Os direitos referem-se à publicação do trabalho em qualquer parte do mundo, incluindo os direitos às renovações, expansões e disseminações da contribuição, bem como outros direitos subsidiários. Todos os trabalhos publicados eletronicamente poderão posteriormente ser publicados em coletâneas impressas sob coordenação da Sustenere Publishing, da Companhia Brasileira de Produção Científica e seus parceiros autorizados. Os (as) autores (as) preservam os direitos autorais, mas não têm permissão para a publicação da contribuição em outro meio, impresso ou digital, em português ou em tradução. 